\title{
Cloud-based Generation and Transfer of Solar Power in a Global Scale
}

\author{
R. Srinivasan, $\mathrm{PhD}$ \\ Fellow Computer Society of \\ India, Member IEEE \\ Emeritus Professor \\ M.S. Ramaiah Institute of \\ Technology \\ Bangalore, India
}

\author{
S.S. lyengar, $\mathrm{PhD}$ \\ Fellow IEEE \\ Ryder Professor and Director \\ School of Computing and \\ Information Sciences \\ Florida International University, \\ Miami, Florida, USA
}

\author{
J.F. Miller \\ Colonel, USAF (Ret.) \\ Research Coordinator, \\ Discovery Lab \\ School of Computing and \\ Information Sciences \\ Miami, Florida, USA
}

\begin{abstract}
One of the most important resources we need today is electricity to carry out comfortably our day-to-day activities. While many nations in the world are abundantly enjoying this resource, more than 1.2 billion people do not have access to electricity. Most of these people are from developing nations typically from Africa and India. They happen to be poor and living in remote villages and mountainous terrains. Several agencies like the World Bank, UNDP, IEA and some developed countries are already taking steps to alleviate this energy poverty with the aim to achieve universal access to electrical power by the year 2030. These efforts are being implemented through well-known methods of electrical power production-both renewable as well as other types, one of which is harvesting the solar energy.
\end{abstract}

As we know, sunlight is not available continuously, 24 hours per day. But what if we could make it so? Since one half the earth's hemisphere does have sunlight, while the other half experiences night time, what if donor countries having the sunshine store the solar energy so it could be used during the night in receiver countries augmented by other types of electrical power? If one such country has excess solar energy, that portion can be transmitted to the country in need. While the infrastructure to directly transfer the energy may be cost prohibitive, perhaps it can be transformed and shared indirectly. However, this type of power sharing of solar energy from one country to another has not been investigated so far. As an initial step, we discuss in this paper a novel approach to transfer digitized temperature of molten salt, used to generate solar power. Molten salt-based generation of solar power has been proved to be more productive and cost effective compared to other methods. Many countries such as USA, Germany, France and Spain are adopting Molten Saltbased technology. If these countries are willing, the temperature of the molten salt can be accessed in parallel to their operation, digitized and uploaded into a private cloud, set up by these countries along with a developing nation. The developing nation can then download the digitized temperature and convert it back into electrical power for distribution.

\section{General Terms}

Renewable energy, solar power, cloud-based generation and transfer of power.

\section{Keywords}

Solar Panels, Heliostat, Molten Salt, Transducer, Turbine, Private Cloud.

\section{INTRODUCTION}

Global agencies like UNDP, World Bank, IEA and some rich, well developed countries are actively involved to achieve "Universal Energy Access" (UEA) and sustainable energy by the year 2030. The reason for paying a great deal of attention to this endeavor is due to the present energy divide between developed and developing countries. According to the report of World Energy Outlook, "Developing Asia and sub-Saharan Africa continue to account together, for more than $95 \%$ of those without modern energy access." Across developing countries, the average electrification rate is $77 \%$, increasing to around $91 \%$ in urban areas but only around $65 \%$ in rural areas. More than eight out of ten people without modern energy access live in rural areas.

According to the Energy Poverty Action Initiative of the World Economic Forum, "Access to energy is fundamental to improving the quality of life and is a key imperative for economic development. In the developing world, energy poverty is still rife." "Access to energy is absolutely fundamental in the struggle against poverty," said World Bank Vice President Rachel Kyte. "It is energy that lights the lamp that lets you do your homework, keeps the heat on in a hospital, and lights the small businesses where most people work. Without energy, there is no economic growth, there is no dynamism, and there is no opportunity"[1]. "It is reported that, with lack of electricity, 2.8 billion people use solid fuels like wood, charcoal cow dung and suffer from the thick smoke emanating from them, as a result of which nearly 1.5 million people-mostly children and women suffer from emphysema and other respiratory diseases" [2].

Present day technology to produce electricity makes use of both non-renewable and renewable energy sources. While non-renewable methods may one day deplete the available resources, renewable energy sources promise sustainable abundance without fear of depletion. Typical examples of renewable energy include: solar energy, wind power, hydropower, geo-thermal energy and biofuel. Solar energy provides the easiest and most economically available resource. Fig.1 illustrates potential annual global energy sources, with our current world energy consumption in the middle. Solar renewable energies, represented by the big sphere, far exceed those of other renewable sources represented by the small spheres inside the large solar sphere. Non-renewable total resources are shown to the right. The volume of each sphere is proportional to the amount of energy it represents [2][4][5]. 


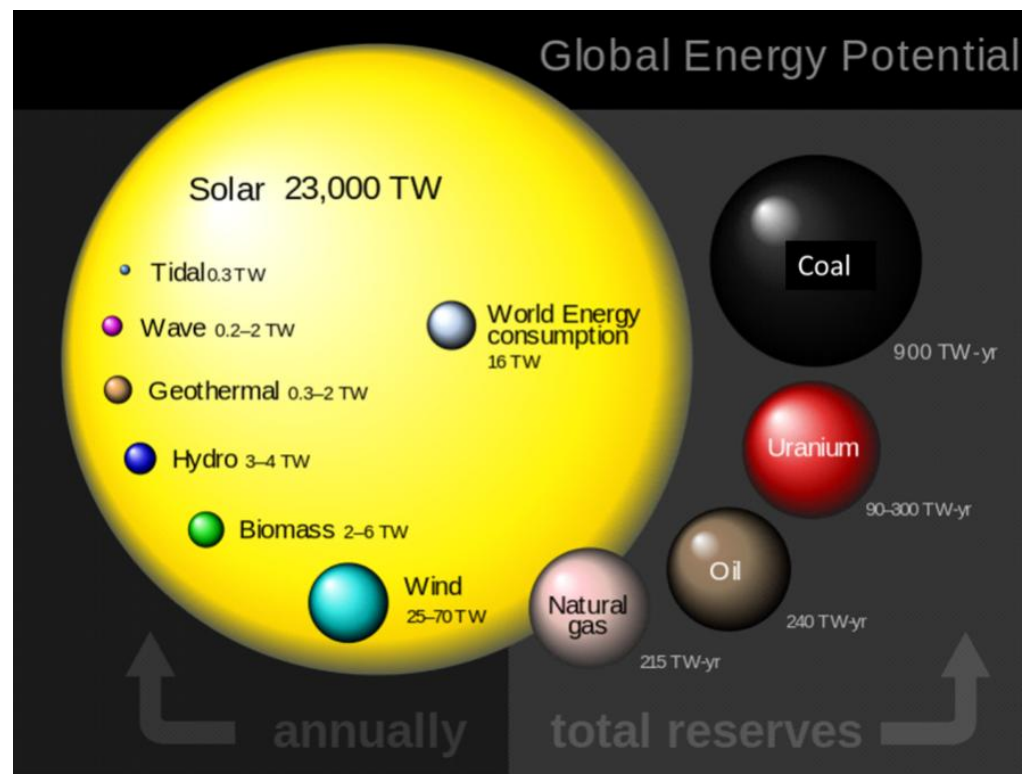

Fig.1. Global Energy Potential[4]

The volume of solar energy availability is, quite obviously, our greatest source of renewable power. As such, solar power development initiatives also receive high levels of support and financial contributions by the World Bank. The World Bank Group committed $\$ 8.2$ billion to support energy finance in 2012. The Bank Group approved a total of $\$ 3.6$ billion in financing for renewable energy projects in fiscal year 2012, a record $44 \%$ share of its annual energy lending. Looking only at power generation projects approved in 2012, renewables accounted for an even larger share as depicted in Fig. 2, as released by the World Bank[2]

Realizing the importance of utilizing solar power, many countries have begun tapping solar energy in a variety of ways for producing electrical power. Methods such as solar panels using photovoltaic cells to convert sunlight directly to electrical power, as well as solar thermal collectors and solar concentration devices have all increased in use. Howeverthe World Bank report stated that, "...the pace of expansion would have to double to meet $100 \%$ energy access targets by the year 2030"[1].

World Bank energy financing in 2014 did increase to $\$ 9.445 \mathrm{~B}$, of which over two-thirds went to regions facing the largest energy deficits-Sub-Saharan Africa and South Asia-with \$3.6B in renewable energy alone-again, one of the strongest years on record for renewable energy lending[3].

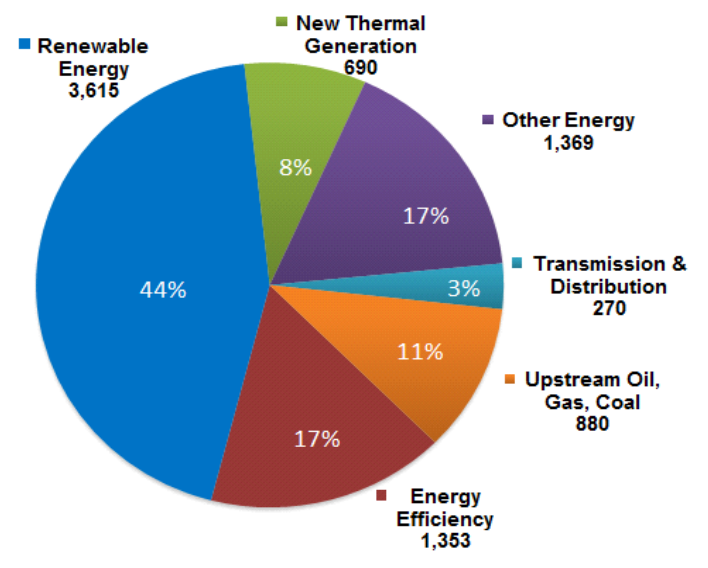

Fig .2. World Bank support for Electrical Power Production

Among the countries that produce electrical power using solar energy, Germany and the USA top the list. In the United States nearly all modern solar panel systems are grid tied which means they're connected to the conventional electricity grid. The solar panels generate power during the day and the excess is fed back into the grid through a system called net metering. When this happens, the electric meter spins backwards and the utility company credits the homeowner for the power produced. At night or on overcast days, houses and factories will use grid power, but will not generally get charged for it because of all the previous solar energy credits generated. This grid-tied method tends to be the most convenient for homeowners. Because of the energy demand in these industrialized countries, however, there may not be excess energy produced. 


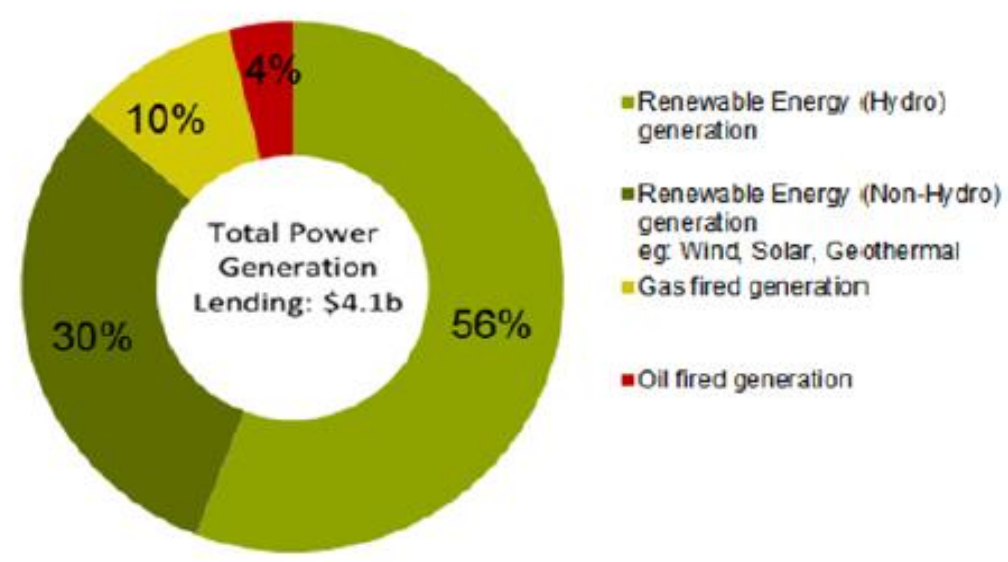

Figure 3. World Bank Renewable Energy Funding 2014[3]

This may not be the case in some other areas of the world, such as sub-Saharan Africa and the Middle-East where large areas of solar radiance are nearly always present, with few users nearby. These countries may have excess solar power which could be produced at low costs without an excessive local demand. To date, no effort has been taken to produce and share this excess solar power from these countries with other poor, energy needy nations.

Our paper concentrates and describes a possible approach to share excess thermal energy produced by focusing the high intensity solar energy from heliostats onto liquid molten salt, then converting this excess thermal energy into digital form in order to transfer it in a private cloud. The private cloud would be established by an agreement between the energy rich nations and the needy country in order to transmit this digital information and convert it to a suitable form to run the turbine of an electrical power generator. It is also possible that more than one developed country that has such excess thermal power from solar radiation, may become part of the private cloud. This excess power from each of these countries can be accessed from the private cloud by the needy country to form a power grid for further transmission..

\section{SOLAR POWER CURRENT PRODUCTION USING THERMAL ENERGY}

While many technologies are available for storing the solar energy, two techniques used to capture solar power and thereby produce electricity, show the most promise. These methods are direct collection using photovoltaic cells and indirectly using Concentrated Solar Power (CSP) to produce thermal energy for conversion to electricity. Photovoltaic cells are most appropriately used for direct electricity production with excess power usually sold back to an electric grid, or captured in battery storage for later local use. CSP on the other hand has the potential for delayed electrical production.

CSP was first developed in 1980's. By tracking the sun light using heliostats and focusing it using mirrors or lenses onto an appropriate material thus, solar energy is converted into heat energy. The heat is then passed on to a conventional generator for producing electricity. In CSP electrical production, "The power plant will consist of two parts: one that collects solar energy and converts it to heat, and another that converts the heat energy to electricity"[7]. "CSP is being widely commercialized and the CSP market has seen about
740 MW of generating capacity added between 2007 and the end of 2010. More than half of this (about $478 \mathrm{MW}$ ) was installed during 2010, bringing the global total to $1095 \mathrm{MW}$. Spain added $400 \mathrm{MW}$ in 2010, taking the global lead with a total of $632 \mathrm{MW}$, while the US ended the year with $509 \mathrm{MW}$. The Middle East is also ramping up their plans to install CSP based projects and as a part of that plan, Shams-I the largest CSP Project in the world has been installed in Abu Dhabi. CSP growth is expected to continue at a fast pace. As of January 2014, Spain had a total capacity of 2,204 MW making this country the world leader in CSP"[7].

Common technologies used in CSP today are: Parabolic Trough, Enclosed Trough, Fresnel Reflector and Solar Power Tower. "Power-tower development is less advanced than trough systems, but offers higher efficiency and better energy storage capability. The SolarTwo in Daggett, California and the CESA-1 in Plataforma solar de Almería, Almería, Spain, are the most representative demonstration plants. "The Planta solar 10 (PS10) in Sanlúcar la Mayor, Spain, is the first commercial utility-scale solar power tower in the world"[8].

Because the popularity and efficiency of CSP, our proposed system will deploy CSP using a Solar Power Tower, with dual axis reflectors called heliostats. We suggest molten salt as the receiver of the focused beam of sunlight from the reflector as the medium for thermal energy storage. Thermal storage is expected to be the future because it offers a "zero-emissions" technology with firm capacity and "dispatchability" characteristics. "The molten salts are synthetic salts, comprising Eutectic mixture of $53 \mathrm{wt} \%$ potassium nitrate, 40 wt $\%$ sodium nitrite, $7 \mathrm{wt} \%$ sodium nitrate. This is a solid product with a melting temperature of 288 degree Fahrenheit to 293 degree Fahrenheit. The main advantage of the molten salt receiver is that it can be heated to 1059 degrees Fahrenheit for efficient heat transfer"[9]. 


\section{CASE STUDY}

A typical 110 MW Solar Power station using Power Tower and Molten Salt technology built near the town of Tonopah in the Nevada desert is shown in Fig. 4. Two storage tanks are used. A cold tank stores the salt at $280^{\circ} \mathrm{C}$, pumps it up to the top of the tower where it circulates through the receiver, where the salt's temperature is taken to $565^{\circ} \mathrm{C}$. It is then piped back down to the hot storage tank. Stored thermal energy in the form of liquid molten salt can be stored for later use or used immediately. The temperature of the liquid can be maintained for a minimum 6 to 8 hours[9].

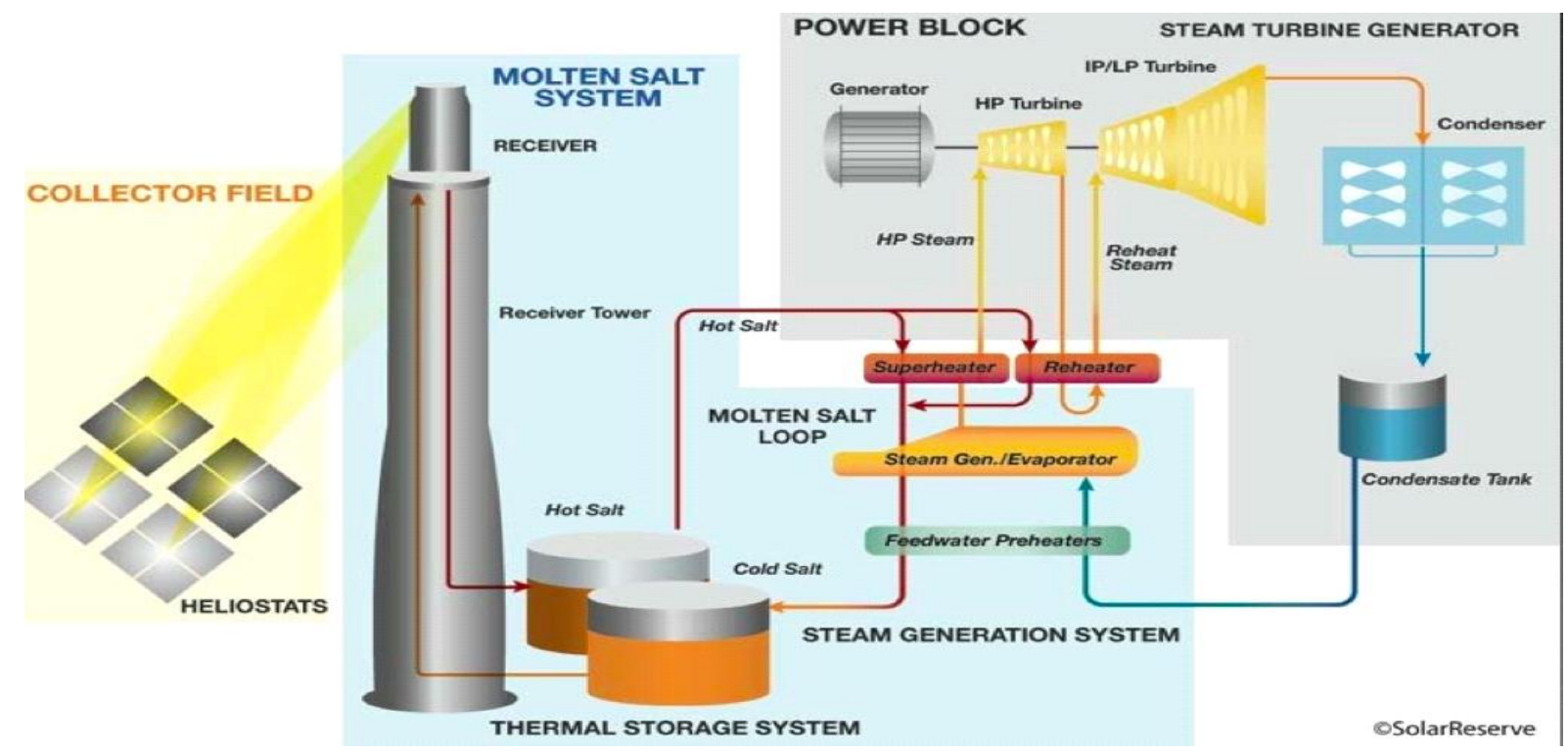

Fig .4. A 110 MW Power station with Molten Salt (Courtesy SolarReserve)

"Gemasolar [10] is a Concentrated Solar Powerplant with a molten salt heat storage system. It is located within the city limits of Fuentes de Andalucía in the province of Seville, Spain. The plant is a $140 \mathrm{~m}$ high solar Power Tower and uses concepts pioneered in the SolarOne and SolarTwo demonstration projects, using molten salt as its heat transfer fluid and energy storage medium." Giles Parkinson [11] wrote an article on 14th October 2013, titled, "World's Largest Solar Thermal Plant With Storage Comes Online," saying that the 280 MW Solana Generating Station constructed by Spanish group Abengoa, S.A., has six hours of molten storage capacity that will allow it to produce energy into the evening, and deliver output according to the needs of the customer."

\section{COUNTRY-TO-COUNTRY CLOUD- BASED SOLAR ENERGY TRANSMISSION}

The world scenario at present, with respect to production of Electrical Power, is that some developed countries have the infrastructure and finance to generate a large amount of electricity with different techniques, particularly using Solar Energy. But there are under developed countries which face acute shortages of electricity. Also more than 1.2 billion people in the world do not have electricity. The majority of these people live in remote areas and terrains. In this paper, we contemplate an approach to investigate if there is a suitable means for solar energy converted into thermal energy from a developed nation to be siphoned out to a needy country and then used to produce electrical power.

Our architecture consists of two parts:

* The country with excess solar, willing to share with the needy, as a "Donor Country," and

* The country that looks forward to receiving this energy as the "Receiver Country"

\subsection{The Donor Country Side}

\subsubsection{The Molten Salt-based Power Generation System:}

Since 2013, molten salt, which has several advantages over oil, has been used as a good heat exchanger in electrical power generation. As shown in Fig. 5, the system consists of a power tower with the proper heliostat that tracks the sun during the daytime so that maximum amount of the sun's light is focused as a concentrated beam onto the container having the molten salt. In a typical power generating system like the Andasol-1 power plant in Spain, the molten salt used is a mixture of sodium and potassium nitrates. The plant is capable of pumping out electricity at $50 \mathrm{MW}$ for nearly 8 hours after sunset. The operating region for the mixture of $60 \%$ wt of Sodium Nitrate and $40 \%$ wt of Potassium Nitrate is $260^{\circ} \mathrm{C}$ to $550{ }^{\circ} \mathrm{C}$. We have to take proper precaution to make sure that the temperature does not go below $260^{\circ} \mathrm{C}$ because it solidifies around $240^{\circ} \mathrm{C}$. The normal operating temperature of the molten salt is around $400^{\circ} \mathrm{C}$ when it transforms into perfect hot liquid to exchange the heat to the steam generator. The hot super-heated steam at a high pressure is passed on to the turbines which rotate at a high speed to generate electricity in the conventional manner.

Since they are conventional power sources, the power generation system involving the steam generator, the turbine and the electrical power generator are not included in this paper.

Our aim is to make use of the thermal energy of the molten salt to generate electricity in the Receiver Country. As it is not possible to directly transmit it, we have to adopt an indirect method. So it is imperative that the temperature of the molten salt first be suitably sensed and recorded. 


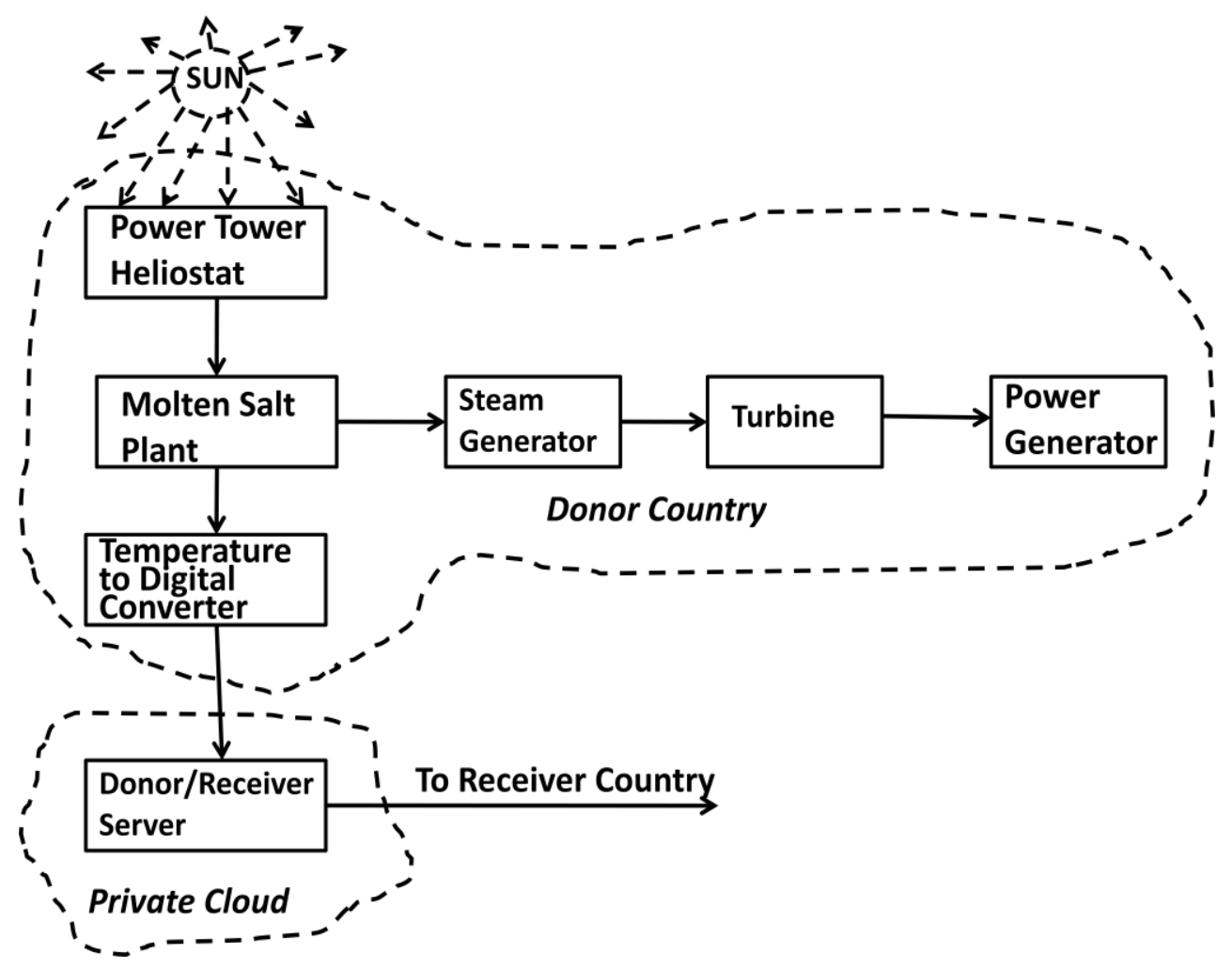

Fig. 5. Structure on Donor Side

This analogue quantity is converted into a 10-bit digital format to be stored in the buffer of the designated Donor/Receiver server located inside the private cloud. We are proposing Private cloud because of its reliability and security.

\subsubsection{Temperature to Digital conversion of the Molten Salt:}

The temperature of the molten salt being high, (around $400^{\circ} \mathrm{C}$ ), requires the use of special sensors, such as Resistance Temperature Detector (RTD) or Noble metal-based thermocouple. Companies like Sensata Technologies, and Picotech, manufacture RTD's; while Stone Ridge Inc. produces thermocouple type sensors. The problem that has to be faced in both cases is that their respective outputs have to be converted to suitable voltage which will be compatible with the Analog to Digital Converter (ADC) Input. That is, the resistance output corresponding to the molten salt temperature of the RTD has to be converted to voltage by passing suitable current through the sensor. Care has to be taken to see that local heating does not upset the measured temperature. In the case of the thermocouple-based sensor, the millivolt output has to be amplified to suit the ADC.

Suppose v1andv2 are the respective minimum and maximum voltage outputs of the temperature sensor system corresponding to the minimum and maximum temperatures needed to keep the molten salt in a liquid form to produce electrical power.

For a 10-bit ADC, the number of levels, is 0 to1023, of the Arduino's 5V system,

Table 1 illustrates Arduino 5Volts - 10 bit ADCdeployed to convert molten salt temperature to digital form. $\underline{\text { Resolution of } \mathrm{ADC}}=\underline{\mathrm{ADC} \text { Reading }}$

System Voltage Analog voltage Measured If 5 volts corresponds to maximum reading of the 10-bit ADC, i.e., 1023,

\section{ADC Reading $\quad=1023$ \\ Analog voltage Measured 5}

- Example:The operating region for the mixture of $60 \% \mathrm{w}$ of Sodium Nitrate and $40 \% \mathrm{w}$ of Potassium Nitrate is $260^{\circ} \mathrm{C}$ to $550^{\circ} \mathrm{C}$. We have to take proper precaution to make sure that the temperature does not go below $260{ }^{\circ} \mathrm{C}$ because it solidifies around $240{ }^{\circ} \mathrm{C}$.

- If 5 volts corresponds to 1023 , ADC Reading/Analog voltage Measured $=(1023 / 5)$.

- If the analogue voltage input is 2 volts (this will be between $v_{1}$ and $v_{2}$ ), the corresponding ADC reading will be $409=(0110011001)_{2}$. For any voltage less than $v_{1}$, the ADC output will be $(0000000000)_{2}$. Corresponding to the maximum temperature $560^{\circ} \mathrm{C}$, the ADC output will be $(1000110000)_{2} .240$ degrees $=0011110000$ 


\section{Arduino 5Volts - 10 bit ADC \\ Table 1: ADC Output $=[$ Analogue Voltage Measured x1023 $] / 5$}

\section{Temperature of Molten Salt Degree Centigrade}

240

260

300

350

400

450

500

560

\author{
Voltage Measured \\ Volts
}

$1.17 \mathrm{~V}$

$1.27-v 1$

1.47

1.71

1.96

2.19

2.44

$2.73-v 2$
ADC Output

0011110000

0100000100

0100101100

0101011110

0110010000

0111000010

0111110100
The digital output of ADC is stored in a buffer at the output of the ADC. The countries involved should set up a private cloud (say) either from Google or Amazon. Using the appropriate cloud instance the contents of the buffer are uploaded into a designated folder in the cloud. If there is more than one donor, a similar procedure will be followed to upload the respective buffers of the donors. On demand, the receiver will adopt MapReduce technique to download the contents of the appropriate buffer and convert it to analogue voltage. This will be applied to a suitable circuit to provide the required field voltage to drive the shaft of the turbine generator.

\subsection{The Receiver Country Side}

The proposed schematic on the side of the Receiver Country for data acquisition from Donor/Receiver Cloud Buffer and power production is show in Fig. 6,below. The system consists of a 10-bit input buffer which, when enabled, will receive the 10-bit output, of the ADC of the donor country, which is stored in the buffer of the private cloud.

The Enable trigger pulse of the Digital to Analog Converter (DAC) will activate the DAC to produce the output voltage, V1, which indirectly represents the temperature of the Molten Salt.

As the temperature of the Molten Salt in the Donor Country varies, the output voltage (V1) at the output of DAC will also vary. But in order to have a stable and constant voltage at the input of the differential amplifier, the output of the DAC is fed to a Texas Instruments TPS55065 DC-DC converter that gives a constant output of $5 \mathrm{~V}$ as shown in Figure 6.
Initially the inverting input of the Difference Amplifier is set at $-10 \mathrm{~V}$ using the potential divider circuit connected between $10 \mathrm{~V}$ and $+10 \mathrm{~V}$. The Preset input of the 10-bit buffer is set such that the output of the DC-DC Converter is the minimum value of $1.5 \mathrm{~V}$ leading to a small positive voltage on the noninverting input of the Operational amplifier. This leads positive saturated voltage at the output of the Operational amplifier and hence the output voltage of the power amplifier drives the motor resulting in the motor shaft rotating at low speed. The incremental optical encoder attached to the shaft of the motor produces optical square pulses that are converted to electrical square wave pulses by the squaring circuit which has a sensor to covert optical pulses to electrical pulses.. The Frequency to Voltage converter converts this into DC voltage that is fed to the non-inverting input of the Op Amp. This continuous phenomenon of negative feedback makes the shaft rotate faster and faster thereby increasing the frequency of the square wave output and hence the output of the F/V converter. Now the 10-bit buffer is enabled so that the Digital equivalent of the Molten Salt temperature, stored in the Private Cloud and transferred to the buffer on the receiver country, will take charge of controlling the motor speed. Once the inverting input reaches the voltage of non- inverting input of the operational amplifier, the motor will reach a steady speed and hence will produce electricity. This generator could be a pilot part of a main machine that produces electricity to be supplied to the grid and it may need high excitation. The AC current produced by the pilot generator's windings can be rectified and fed directly to the rotor windings of the main machine to supply the excitation for the main machine. 


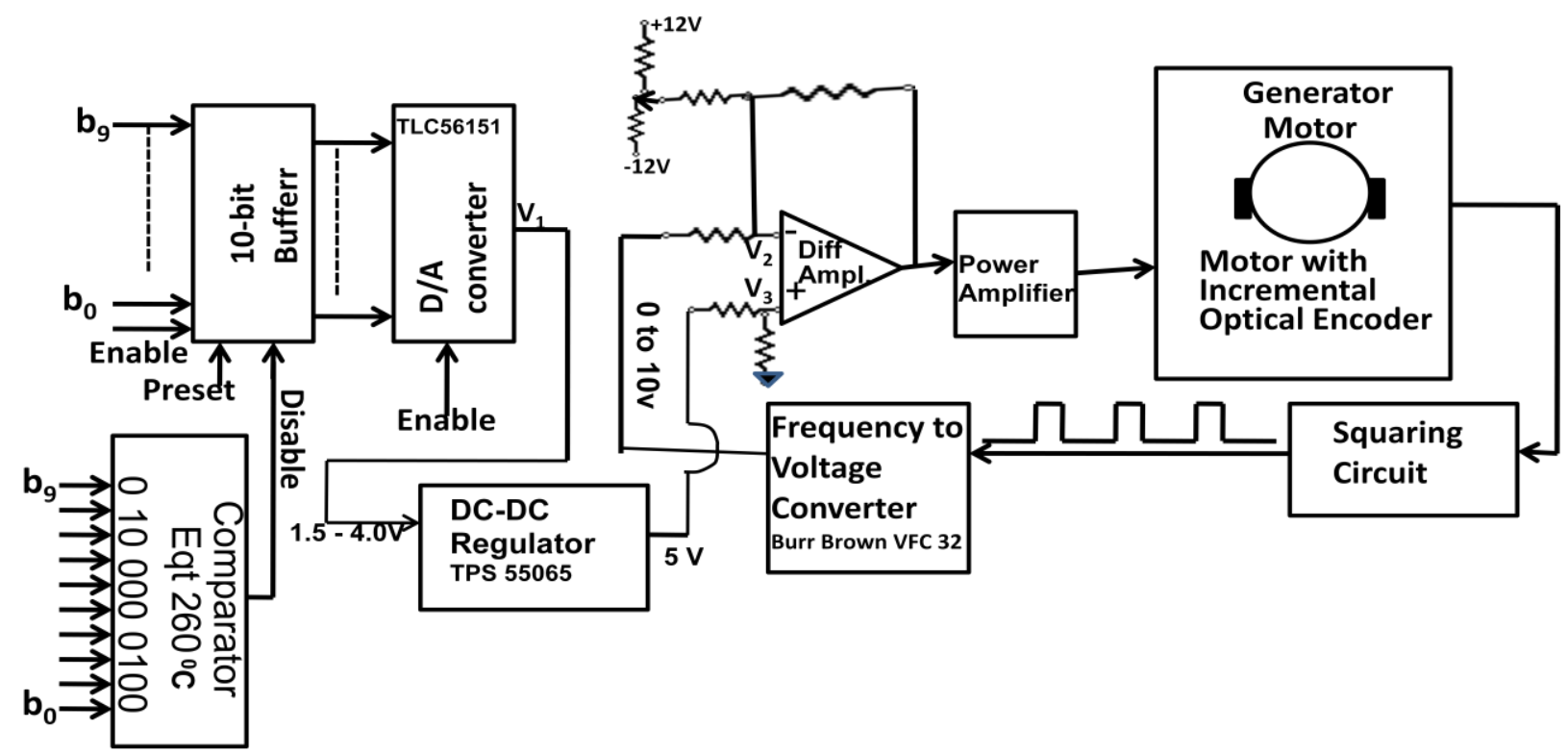

Fig. 6 Data Acquisition and Power Production

Table 2 illustrates the analogue output (V1) of Texas

Instruments TLC5615I DAC, fed as input to the Differential

Amplifier.

Table 2:

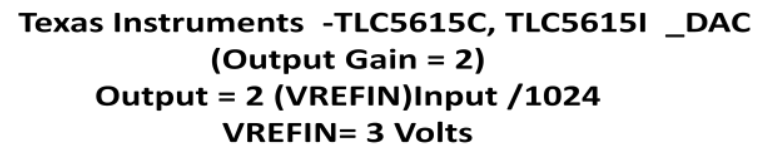

$\begin{gathered}\text { Temperature } \\ \text { Degree Centigrade }\end{gathered}$
560
500
460.8
450
400
350
300
260

\section{Digital Input}

1000110000

0111110100

0110101101

0111000010

0110010000

0101011110

0100101100

0100000100
Analogue Output Volts

3.28

2.93

2.7

2.64

2.34

2.05

1.73

1.52

\section{CASE OF MORE THAN ONE DONOR}

In order to achieve Universal Energy Access by the year 2030, it may be possible that global agencies like UNDP, World Bank, IEA provide necessary support for developing countries to share thermal energy from more than a single Donor Country. As a typical case, if four donors offer to share the thermal energy with a needy nation, through the international monetary funding, a unique "Energy Private Cloud" can be established by all four donors with the Receiving Country. Figure 7 illustrates the data acquisition from the respective Donor Country and power production.

By making use of proper Cloud instance, the digital outputs, represented by Donor- $\mathrm{i}$ ( $\mathrm{i}=1$ to 4 ), of the temperature of the molten salt from each country is uploaded into respective buffer in the dedicated server of the "Energy Private Cloud." The outputs of these buffers are multiplexed by MapReduce technique. Using the Select input, the appropriate donor output is connected as input to the Data Acquisition and Power Production section to produce the electrical power which is fed into a power grid for distribution. 


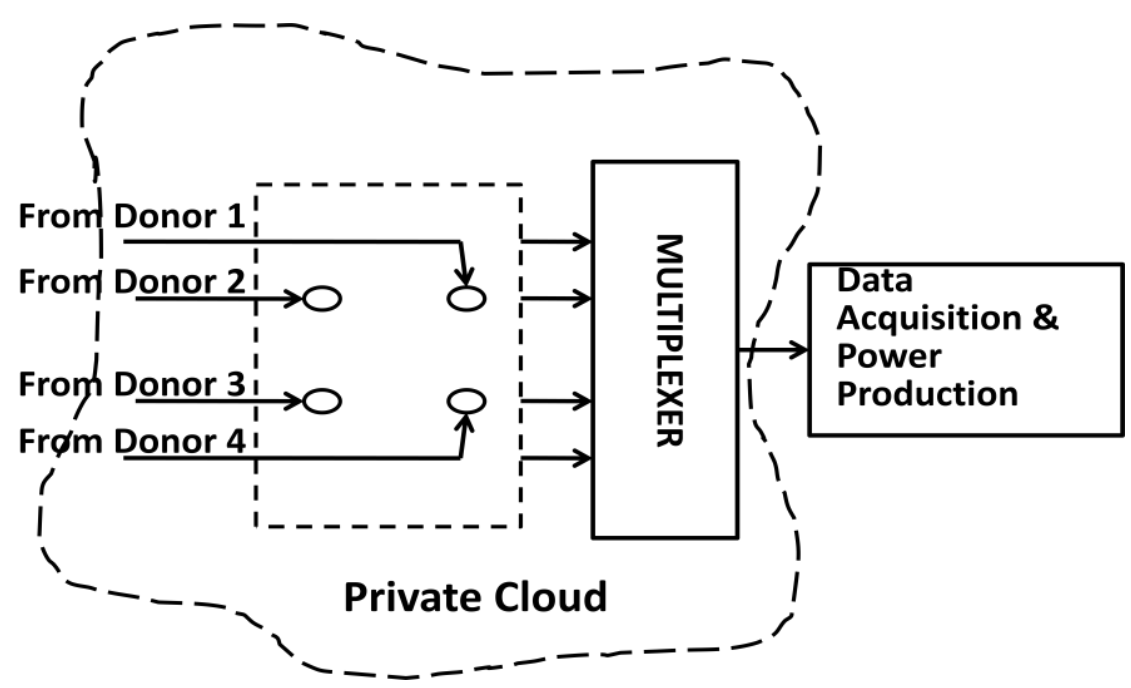

Fig. 7.Data Acquisition and Power Production.

\section{FEASIBILITY}

We present in this paper a novel idea to produce electrical power in a developing country which suffers from acute energy paucity or no power. But the question may be, "How feasible is this concept?"

It is assumed that the countries which produce a lot of electric power using solar energy may have either excess solar energy to spare or allow access to their resource material (solid or liquid) used for heat transfer. The reasons to substantiate the feasibility of our suggestion are:

- One such material, being used by many countries now, is molten salt which is a mixture of Sodium Nitrate and Potassium Nitrate in suitable proportions. Molten salt has several advantages compared to other materials used in generating solar power and has been proved to be cost effective. Molten salt based systems are now producing electrical power on the order of 300-to-500 Mwe, so it is possible to acquire the permission from them, through International Agencies, to access the molten salt bath. (It should be noted that our method does not tap the power generated by such a Donor Country; but only measures and takes the temperature of the molten salt for further processing.)

- All the constituent systems/parts described, both on the Donor Country side as well as on the Receiver Country side, are well established, so no new devices/systems need to be discovered for implementation.

- As the International Agencies like UNDP, World Bank and IEA are already contributing and providing financial support, it is expected that such a project may also be funded.

- We have adequate manpower in the Receiving Country, who can be could be easily trained to operate and maintain the system on their side.

- Solar Energy is the most abundant, continuous source of power available to provide our future energy needs.
- Time taken to execute such a program to produce electricity will be short compared to setting up big power plants in a developing country and also provide a flexible, scalable power solution.

\section{CONCLUSION}

A large portion of the world's population, particularly in developing countries, are facing an acute paucity or complete lack of access to electricity, due to their remote locations. The aim of the International monetary agencies like World Bank, International Energy Agency (IEA), UNDP and others is to achieve universal energy access by the year 2030. Among the different methods of electrical power production for which their support is being given, only the harvesting and use of Solar Energy offers us a continuous, sustainable and scalable power source. Many developed countries have already set up solar energy power stations generating around $350 \mathrm{MW}$ or more. They deploy molten salt, a mixture of sodium and potassium nitrate in proper proportions to produce thermal energy for generating the electrical power. We discuss in this paper a possible method of sharing this thermal energy, in parallel with the developed country, and apply a novel technique to convert the temperature of the molten bath into a digital form, store it in the buffer of a server located in the Private Cloud established between the Donor Countries and the Receiver Country, and then subsequently covert this digitized information into analog voltage for producing electricity on the receiver side. We feel it is feasible to implement this process through international monetary agencies to help a developing country.

\section{REFERENCES}

[1] National Geographic, 2013, May, "Power Paucity," National Geographic, [Online]. Available: http://news.nationalgeographic.com/ National Geographic, Published on May 29, 2013 (under power paucity)

[2] World Bank Staff, 2014, Sept., "World Bank Group Energy Lending Focuses on Poorest Regions - Boost in Renewable Energy Financing," World Bank News, September 9, 2014, [Online]. Available: http://www.worldbank.org/en/news/feature/2014/09/05/b oost-in-world-bank-renewable-energy-lending

[3] World Bank Staff, 2013, May, "Energy Highlights," World Bank, [Online]. Available: 
http://web.worldbank.org/WBSITE/EXTERNAL/TOPIC S/EXTENERGY2/0,,contentMDK:22855502 pagePK:2 10058 piPK:21002 theSitePK:4114200,00.html

[4] R. Perez, M. Perez, 2009 Jan., "A Fundamental Look at Energy Reserves for the Planet," IEA/SHC Solar Update, [Online].Available:

http://en.wikipedia.org/wiki/Renewable_energy\#mediavi ewer/File:Global_energy_potential_perez_2009_en.svg

[5] R. Perez, M. Perez, 2009 Jan., "A Fundamental Look at Energy Reserves for the Planet," IEA/SHC Solar Update, [Online].Available:

http://www.asrc.albany.edu/people/faculty/perez/Kit/pdf/ a-fundamental-look-at\%20the-planetary-energyreserves.pdf

[6] US Department of Energy, National Renewable Energy Laboratory, [Online]. Available: http://solareis.anl.gov/documents/docs/NREL_CSP_1.pd $\mathrm{f}$

[7] J.L. Sawin and E. Martinot, 2011, Sep., "Renewables Bounced Back in 2010, Finds REN21 Global Report," Renewable Energy World, [Online] Available: http://web.archive.org/web/20111102183605/http://www .renewableenergyworld.com/rea/news/article/2011/09/re newables-bounced-back-in-2010-finds-ren21-globalreport
[8] Environmental News Service Staff, 2007, May, "First EU Commercial Concentrating Solar Power Tower Opens in Spain," ENS Newswire, [Online] Available: http://www.ens-newswire.com/ens/mar2007/2007-03-3002.asp

[9] G. Parkinson, 2013, Jul., "How it works: Solar power towers with integrated storage," Reneweconomy, [Online]Available:http://reneweconomy.com.au/2013/ho w-it-works-solar-power-towers-with-integrated-storage78892

[10] The International Resource Journal Staff, 2011, May, "Torresol's landmark Gemasolar CSP solar plant is officially commissioned," The International Resource Journal, May 2011, [Online]. Available: http://www.internationalresourcejournal.com/resource_n ews/torresol_s_landmark_gemasolar_csp_solar_plant_is _officially_comm.htmlandhttp://en.wikipedia.org/wiki/G emasolar_Thermosolar_Plant

[11] G. Parkinson, 2013, Oct., "World's largest solar thermal plant with storage comes on-line," Reneweconomy, [Online]Available:http://reneweconomy.com.au/2013/wo rlds-largest-solar-thermal-plant-with-storage-comes-online-63533 